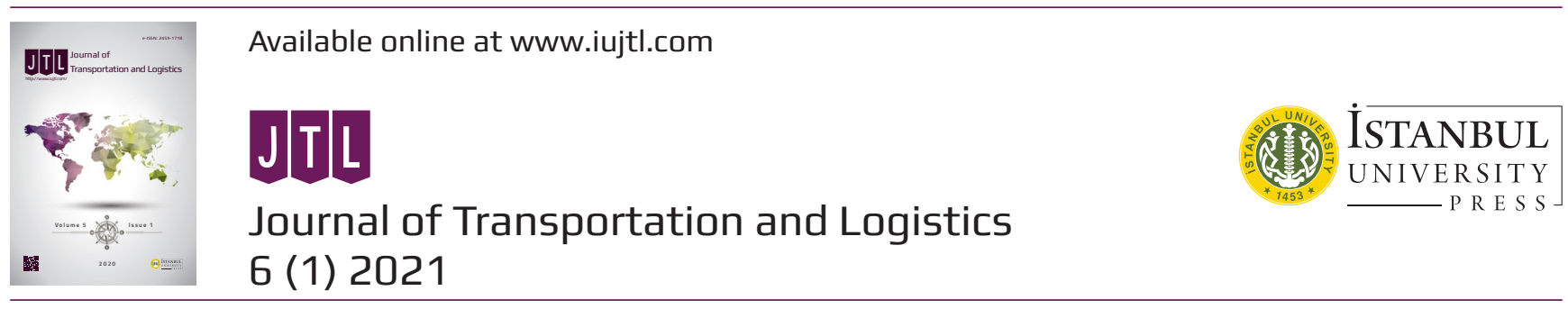

\title{
Minimizing Solid Waste Collection Routes Using Ant Colony Algorithm: A Case Study in Gaziantep District
}

\author{
Katı Çöp Toplama Rotalarının Karınca Kolonisi Algoritması ile Minimizasyonu: \\ Gaziantep'te Bir Uygulama
}

Serap Ulusam Seçkiner ${ }^{1}$ (D), Amanuel Moges Shumye ${ }^{2}$ (D), Sena Geçer ${ }^{3}$ (D)

\begin{abstract}
This paper proposes an ant colony optimization algorithm for a capacitated vehicle routing problem to determine the shortest waste collection and transportation route covered by a waste collection truck in the Şahinbey municipality of Gaziantep/Turkey. The real-case problem concerns a capacity-restricted garbage compactor truck that collects and transports waste from 349 residential waste containers located in 148 collection points. Possible solutions obtained from the ant colony algorithm were compared with mixed-integer programming model solutions. The results of the proposed ant colony optimization algorithm showed that our model yields a $28 \%$ reduction in the total daily traveled distances and energy savings against existing consumption. The new solution also cuts the current annual waste collection and transportation expenditure per vehicle by $30 \%$. It is shown that a considerably shorter route distance obtained in the algorithmic solution helps to reduce air pollution from the infamously inefficient garbage collection trucks. Eventually, the new route will considerably reduce labor costs, the high price of fuel, machinery and equipment maintenance as well as environmental pollution, because garbage compactor trucks are one of the least efficient vehicles on the road.

Keywords: Solid waste management, Route optimization, Capacitated traveling salesman problem, Ant colony optimization, Mixed-integer linear programming
\end{abstract}

Submitted: 11.03.2021 • Revision Requested: 21.04.2021 • Last Revision Received: 26.05.2021 • Accepted: 26.05.2021

1 Corresponding author: Serap Ulusam Seçkiner (Prof. Dr.), Gaziantep Üniversitesi, Mühendislik Fakültesi Endüstri Mühendisliği Bölümü, Gaziantep, Türkiye. E-mail: seckiner@gantep.edu.tr, ORCID: 0000-0002-1612-6033

2 Amanuel Moges Shumye (Lisans öğrencisi), Gaziantep Üniversitesi, Mühendislik Fakültesi Endüstri Mühendisliği Bölümü, Gaziantep, Türkiye. ORCID: 0000-0001-6707-3560

3 Sena Geçer (Lisans öğrencisi), Gaziantep Üniversitesi, Mühendislik Fakültesi Endüstri Mühendisliği Bölümü, Gaziantep, Türkiye. ORCID: 0000-0002-9263-171X

Citation: Ulusam Seckiner, S., Shumye, A. M., \& Gecer, S. (2021). Minimizing solid waste collection routes using ant colony algorithm: A case study in Gaziantep district. Journal of Transportation and Logistics, 6(1), 29-47. https://doi.org/10.26650/JTL.2021.894265 


\section{Introduction}

Strengthening waste management has vital importance for ensuring the sustainable use of natural resources and protection of the environment and human health, and it is a fundamental factor in ensuring a better quality of life for present and future generations (Bilgi 2018). Especially in developing countries such as Turkey, the development of proper waste collection and transportation systems is key to promoting growth in the long term. Being one of the fastest developing cities both in the economy and population in Turkey, Gaziantep is the 6th biggest city of Turkey with a population of 2,5 million residents on a surface area of $6819 \mathrm{~km}^{2}$. The increase in solid waste production has started to become one of the major environmental problems in parallel with the rapid population increase, developing industrialization and changes in the social and economic status of society, and unplanned urbanization in Turkey (Gören et al. 2018). Consequently, Gaziantep is experiencing a high increase in the quantity of solid waste produced each day. However, there has not been much work done to make waste collection efficient and cost-effective.

The existing solid waste collection and transportation system in the Gaziantep metropolitan municipality has a branch of waste management that manages all waste management operations with eight environmental engineers. The solid wastes, medical wastes, waste vegetable oils, and waste batteries in the province of Gaziantep are collected without harming the environment and disposed of through joint works with local administrations, non-governmental organizations, and licensed firms in line with the regulations published by the Ministry of Environment and Urban Planning. Among the different district municipalities, Şahinbey and Şehitkamil collect and transport solid waste to the Gaziantep Metropolitan Municipality Landfill Area. Gaziantep has 2 Landfills; Central Landfill (1500 ton/day) and Nizip Landfill (200 ton/day). Central Landfill, which takes 1.5 million $\mathrm{m}^{2}$ of the area was constructed in 1996 and has a capacity of 30 million $\mathrm{m}^{3}$. Statistics show that 7 million tons of solid waste were stored in the Central Landfill Area between 1996-2015 (Köse et al. 2007). Güneykent is one of the most populated districts in the Şahinbey Municipality. Its solid waste is collected using metal containers each with a capacity of $400 \mathrm{~L}$ as well as plastic-made containers with a capacity ranging up to 770 L. The collection and transportation of solid waste in this district are carried out by using waste collection trucks of varying capacity up to 11 tons of waste operating in a single shift from 3 pm to 10 am daily.

\subsection{Problem definition}

Solid waste collection and transportation constitutes an integral part of solid waste management systems in urban areas, thus comprising the biggest share in the list of costs involved in the municipality Solid Waste Management System (SWMS) including processing, disposal, processing, and other related costs. This critical process should be performed effectively and efficiently to avoid costly expenditures and ensure environmental health. If waste is not collected properly, then nuisance may occur in the waste generation area (Hannan et al. 2017). 
Many issues exist in the SWMS currently in practice in the Şahinbey municipality. In a municipality of over 900,000 residents, there is an obvious lack of an integrated SWMS that combines scientific approaches to best meet the demands of residents in the most economical way. This includes modernizing the heuristic approach followed concerning the assignment of vehicles and scheduling of waste collection activities. Moreover, the traditional judgemental methods used to anticipate the expected fill-up rate of containers, the emptying frequency of dumpsters, and locations of collection infrastructures are largely prone to inaccuracies. This, in return, leads to excessive transportation costs due to the prevalence of zero miles.

A typical waste collection and transportation routine in the Güneykent district is carried out by allocating SWC trucks to collect solid waste from open containers located in predetermined locations using routes that are flexibly determined by truck drivers solely based on their experience and judgment. This intuitive approach to route determination might improve the quality of the total collection and transportation route through time but can only achieve limited accuracy due to its dependency on personal judgment. More than sixty percent of the costs in SWMS in different countries are due to labor costs, the high price of fuel and machinery, and equipment maintenance all of which are highly dependent on the collection and transportation route was chosen (Talebbeydokhti et al. 2013). As a result, the district continues to record high expenditure related to these activities. By identifying this room for improvement, we apply a scientific approach by formulating a capacitated travel salesman problem to optimize the process of route determination in the Güneykent district.

Some research has been made in the area of solid waste collection and transportation systems using different formulation approaches. Most of these experiments have concentrated on optimizing the collection and transportation systems implemented in urban municipalities. More specifically, researchers have conducted a variety of scientific experiments in the area of optimization of municipality solid waste collection and transportation routes by applying conventional, heuristic, and meta-heuristic optimization algorithms. For example, Das and Bhattacharyya (2015) formulated mixed-integer linear programming (MILP) to a route optimization problem and then proposed a heuristic solution for an optimal waste collection and transportation system. Beijoco et al., 2010 modeled the fill-up rate and emptying frequencies of dumpsters to optimize glass waste transportation routes for time and distance by using ArcGIS network analyst software. Bhambulkar (2011) used it to optimize solid waste collection routes by taking into account essential road restrictions. However, all software applications are not up to the mark for solid waste collection optimization. Hanna et al., (2020) searched the waste collection objectives, constraints, and modeling approach for sustainable development. Mamashli and Javadian (2020) proposed a model for optimizing sustainable design modifications of the municipal waste management network. Mojtahedi et al., (2021) studied solid waste management for sustainable vehicle routing problems. Liu and Liao (2021) tackled a two-echelon collaborative waste collection routing problem from an optimization and profit perspective. 
Another group of more advanced optimization methodologies are being used in this area is meta-heuristic optimization algorithms. These methods have become increasingly popular in studies conducted in recent years. One of those approaches was implemented by Hannan et al. 2017, where a modified particle swarm optimization algorithm (PSO) was used to solve a capacitated vehicle routing problem. Karadimas et al. 2007 applied the genetic algorithm to minimize solid waste collection routes, and Islam and Rahma (2012) implemented the ant colony algorithm with different constraints including time windows, driver rest periods, and multiple disposal facilities.

These studies have investigated the relative performance of different optimization techniques to formulate and optimize real-world solid waste collection and transportation routes. Among municipal waste management studies, it can be mentioned about some research. For example, Nguyen et al., (2021) compared six data-driven machine-learning methods to predict municipal solid waste generation and random forest and k-nearest neighbor were the most effective algorithms. For readers, Abdallah et al., (2020) published a review of artificial intelligence methods for solid waste management. This review provides a comprehensive analysis of the different Artificial Intelligence models and techniques applied in Support Vector Machine application, domains, and reported performance parameters.

It is impractical to find the shortest paths of a Travelling Salesman Problem (TSP) consisting of a large number of destinations, as the problem becomes exponentially difficult with increasing locations. Especially during combinatorial problems where the solution space of the existing network is vast, exact optimization techniques such as mixed integer programming fail to give reliable solutions in practical computation time. Heuristic approaches, on the other hand, have been proved, in different route optimization problems, to give near-optimal solutions within a reasonable amount of time.

\subsection{Objective and constraints}

This paper attempts to optimize solid waste collection and transportation routes currently in practice in the Güneykent district of Şahinbey municipality to minimize the costs associated with solid waste collection and transportation activities including labor costs, fuel consumption, and vehicle maintenance and operating costs. This reduction in fuel consumption will eventually contribute to the reduction of environmental emissions and global warming. Optimization for distance will also increase the efficiency of the SWMS as the same; even better, activities are performed at less cost and relatively less time.

Below is a more specific and detailed description of the main objectives and sub-objectives of this study:

- Determining the shortest path followed by a garbage compactor truck that collects and transports solid waste from 349 residential waste containers to a disposal ground in the Güneykent district of Şahinbey municipality,

- Testing and investigating the performance of an ant colony algorithm optimization (ACO) approach to a capacitated travel salesman problem, 
- Comparing the optimized routes generated by a meta-heuristic method (ACO) with that of an exact method (mixed-integer linear programming),

- Performing performance analysis of ACO and mixed-integer programming by studying their computational time in solving small scale TSPs

- Evaluating the quality of the existing solid waste collection and transportation route by comparing it to near-optimal routes developed through ACO.

Gaziantep city has an SWMS that consists of hundreds of vehicles and tens of thousands of containers. To best understand the effectiveness of the proposed optimization methods, the area of this investigation is concentrated on a specific region in the city of Gaziantep, where a comparatively organized waste collection routine is observed. The availability of complete geographical information on the location of solid waste containers, ease of access to the required data, and the presence of fixed vehicle scheduling are some of the most important factors that are taken into account when determining the scope of this study.

The vehicle (garbage compactor truck) in our study has an important capacity constraint that hinders it from visiting all the collection nodes in a single tour. Therefore, we developed our problem as a capacitated travel salesman problem (CTSP) which is different from a typical TSP. A CTSP is a routing problem in which a vehicle has a limited capacity that prevents it from visiting all locations in one tour, thus necessitating a second return tour. Our problem has been formulated as a CTSP during which each time the garbage compactor truck visits a point of residential waste containers its capacity decreases. After it has collected waste from a fixed number of points the truck has to travel to a disposal ground to unload and then return to the remaining points to complete its tour. The vehicle in our study has a capacity of carrying garbage from 200 - 205 containers in a single tour.

\section{Materials and methods}

As mentioned earlier, the determination of the area of our study aimed at finding a region that will help us effectively demonstrate the performance of the ACO algorithm implemented in our study. The Güneykent district was determined to be the most suitable region for our study as it has stationary and better organized waste container locations. We have also found it comparatively easier to access information from the Şahinbey municipality than other municipalities.

Once the type of problem and the location of the study was decided, several procedures were followed to gather the necessary information needed to conduct the research. To facilitate data collection, questionnaires and interviews were prepared. Information regarding the existing solid waste collection and transportation system was mainly collected through multiple interviews with the director of waste management services at the Şahinbey Municipality and environment and the vice president of the Şahinbey municipality. Some interviews were undertaken with specific discussions on the number of containers and locations, the type, capacity, and the number of waste collection trucks used, the operation mode of the existing waste collection and transportation, etc. An important part of the data collection process was the field survey where accurate information on the location of containers was obtained. 
In the following stages of the project, Google Maps was utilized to organize and integrate the qualitative, numerical, and geographical data collected. Furthermore, tasks including geographical analysis, visualization, editing, and data conversion were performed on a geographical information system software called ArcGIS. ArcMap, the main component of ArcGIS, has many toolboxes included such as conversion tools, network analysis, and data management tools. These tools were also especially helpful in generating the distance matrix and determining the current waste collection and transportation routes. A distance matrix containing the shortest driving distances between each of the containers was generated using the ArcMAP's network analyst tool.

To find a near-optimal solution to the given capacitated travel salesman problem in a reasonable amount of time, the ACO algorithm approach was used. This algorithm is preferred over exact methods to solve combinatorial routing problems since even though the latter guarantees optimal solutions, it is extremely time-consuming, especially in cases of large combinatorial problems such as ours. However, we have also tried to propose a model of a smaller version of our original CTSP using mixed-integer linear programming, and compared its performance with that implemented using the ACO algorithm.

MATLAB R2018b was employed to formulate an ACO algorithm of the capacitated travel salesman problem. Further graphical analysis, the tuning of parameters, and the evaluation of solutions were also carried out on the same platform. As a test study, the optimization modeling software LINGO was also utilized to formulate a mixed integer programming model of a lower-scale TSP with 9 stops collection. The block diagram of the proposed method is given Figure 1.

\section{Capacitated Travelling}

Salesman Problem
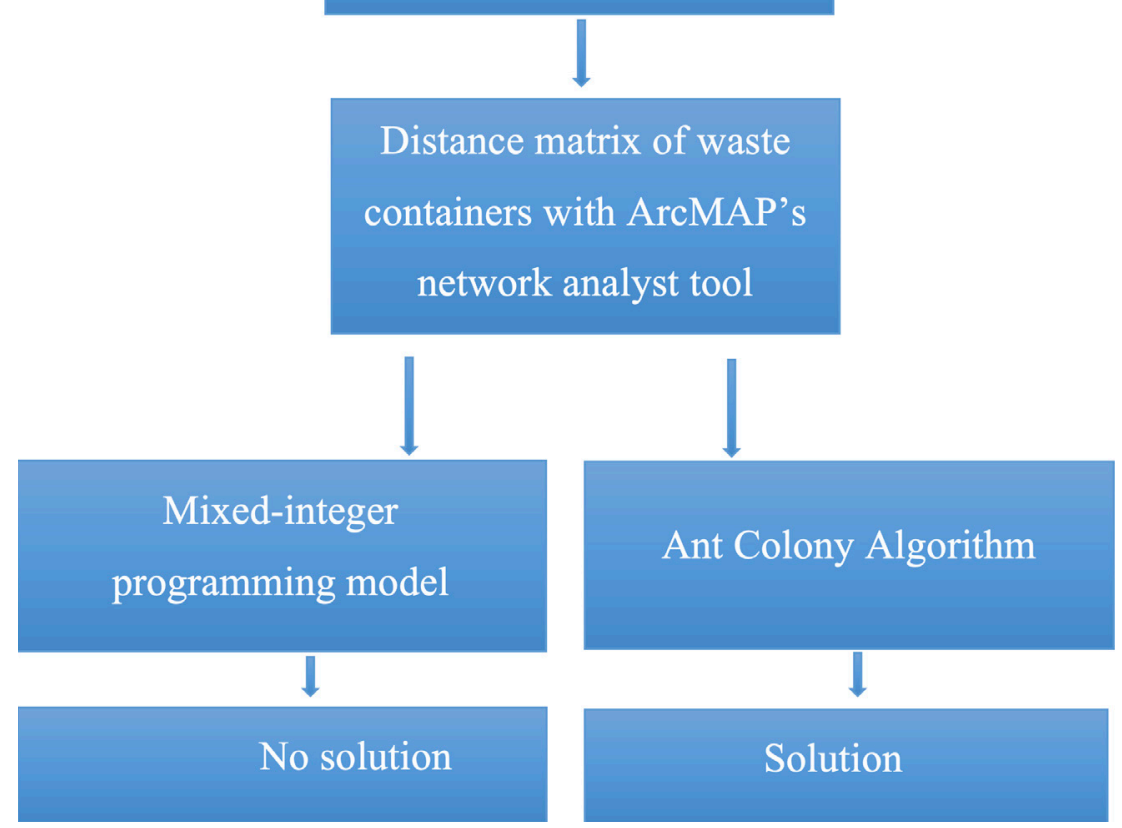

Figure 1. Block diagram of the proposed method 


\subsection{The Ant Colony Optimization}

Ant colony optimization is a population-based metaheuristic that can be used to find approximate solutions to difficult optimization problems (Dorigo 2007, Dorigo \& Stützle 2004). Artificial ants are forms of coordination that exhibit the properties of real ants but are used to model and solve complex combinatorial problems using an ant colony algorithm. Artificial ants can be considered as paths. Shortest path problems such as TSP can be modeled as a problem where an ant colony tries to determine the shortest path from its nest to a food source.

The probability of an ant colony to choose the next edge depends on two important parameters; the pheromone deposition on and the desirability of the edges attached to the current node. Pheromone deposition refers to the level of pheromone present on a given edge at the time of decision (after pheromone updating and evaporation have been carried out). This way edges that have high pheromone concentration will have a greater probability of being chosen than those with low pheromone deposition, meaning they have been visited less frequently by earlier ants. An ant colony also considers the desirability of an edge before deciding on choosing the next edge of its tour. This parameter is inversely proportional to the relative length of an edge; the shorter the path, the higher the probability of an ant choosing it and vice versa.

To express the relative weight (importance) of these two factors on decision making ACO uses two more parameters; pheromone heuristic factor $(\alpha)$ and expected heuristic factor $(\beta)$. The pheromone heuristic factor expresses the power of pheromone that emphasizes the influence of the pheromone deposition on decision-making, whereas the expected heuristic factor expresses the relative weight of the desirability (quality) of an edge on calculating the probability of choosing a path. Optimizing these parameters helps to improve the convergence speed and global optimization ability of the algorithm (Chen 2016).

The general mathematical formulation of an Ant System (AS) for a TSP consists of three important components. We first need to simulate the concept of pheromone trails mathematically. Then, the pheromone equation should be modified to account for pheromone update and volatility (evaporation). Given that information, the probabilistic decision for constructing the solution is formulated. The roulette wheel selection procedure is then utilized to select potential solutions using the calculated probabilities.

Given an ant $k$ in a colony of ants, the pheromone laid by ant $k$ on the path between nodes $i$ and $j$ is given by (see Eq.1):

$\Delta \tau_{i, j}^{k}=\left\{\frac{1}{L_{K}}\right.$, if the $k$ th ant travels on the edge $i, j$

where $\mathrm{L}_{\mathrm{k}}$ is the length of the tour of the $k^{\text {th }}$ ant

$0, \quad$ otherwise 
The pheromone deposited by all ants on the edge $i, j$ before the effect of evaporation is expressed as in Equation 2:

$\tau_{i, j}^{k} \quad=\quad \sum_{k=1}^{m} \Delta \tau_{i, j}^{k}$

where $\Delta \tau_{\mathrm{i}, \mathrm{j}}^{\mathrm{k}}$ is the amount of pheromone deposited by ant $\mathrm{k}$ on the edge $i, j$

$m$ is the number of ants

The previous equation can also be adjusted to include the effect of evaporation on the pheromone concentration of each edge (see Equation 3):

$\tau_{\mathrm{i}, \mathrm{j}}^{\mathrm{k}}=(1-\rho) \tau_{\mathrm{i}, \mathrm{j}}^{\mathrm{k}}+\sum_{k=1}^{m} \Delta \tau_{\mathrm{i}, \mathrm{j}}^{\mathrm{k}}, \quad 0 \leq \rho \leq 1$

where $\rho$ is the rate of evaporation

Whenever an ant $k$ reaches certain node $i$, the decision of choosing the next edge of its tour $(i, j)$ is given by the following probability (see Equation 4 ):

$\mathrm{P}_{\mathrm{i}, \mathrm{j}}=\frac{\left(\tau_{i, j}\right)^{\alpha}\left(\eta_{i, j}\right)^{\beta}}{\sum\left(\tau_{i, j}\right)^{\alpha}\left(\eta_{i, j}\right)^{\beta}}, \quad \eta_{i, j}=\frac{1}{\mathrm{~L}_{\mathrm{ij}}}$

Where $\eta_{i, j}$ indicates the desirability of the edge $i, j$

The roulette wheel selection procedure assigns the next point of the tour based on calculated cumulative sums and random number generation. The process has three main steps:

- Calculate the cumulative sum for each of the $n$ candidate edges using their probabilities

- Generate a random number $r(0 \leq r \leq 1)$

- Use the calculated cumulative sums as upper and lower limits to divide $r$ into $n$ intervals

- The next edge is the edge whose cumulative sum is the upper limit of the interval in which the random number $r$ falls

\section{Case study}

A geographical analysis of the spatial data has been carried out to generate inputs that would feed the algorithm, including location coordinates and a distance matrix. Our problem has been formulated as a CTSP during which each time the garbage compactor truck visits a point of residential waste containers, its capacity decreases. After it has collected waste from a fixed number of points the truck has to travel to a disposal ground to unload and then return to the remaining points to complete its tour. The garbage carrying capacity of the vehicle has been determined to be 200-205 containers on a single tour. Therefore, the algorithm had to be developed by considering this capacity constraint.

\subsection{Geographical analysis}

As a result of the field survey, the total number of residential waste containers in the area of study has been determined to be 349 . To facilitate effective analysis of the routing problem, the container system has been divided into 148 points of a collection each containing 
varying numbers of residential waste containers ranging from 1 to 12 depending on the location of the point. A geographical view of the location of residential waste containers in the Güneykent district is given in Figure 2 scale as 1:12,500.

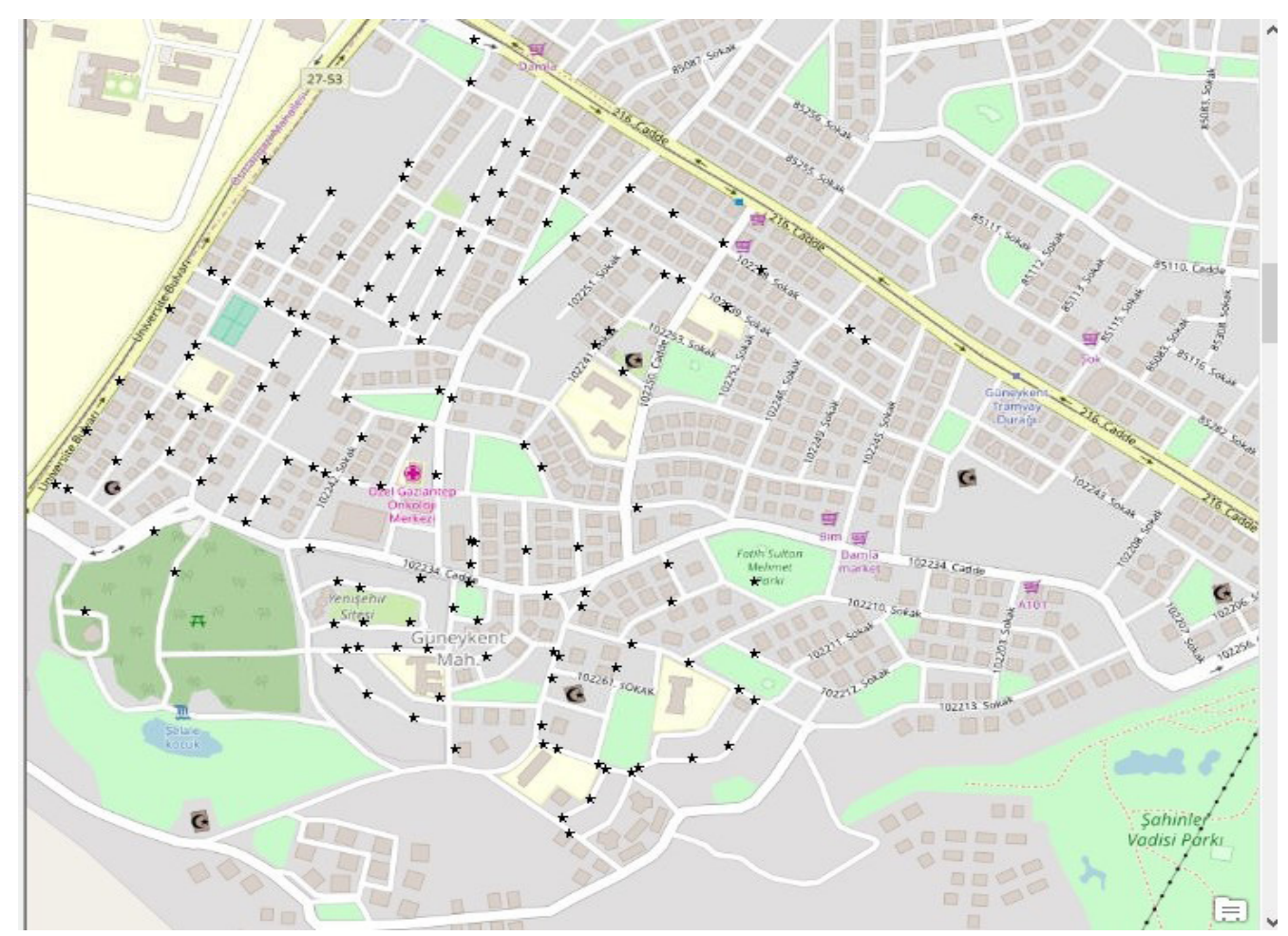

Figure 2. A geographical view of the location of residential waste containers in Güneykent district

Once the required data on the location of residential waste containers were gathered, it was integrated with other qualitative, numerical, and geographical data using ArcMAP. Primarily, the location of each point has been converted from geographical to cartesian $(x, y)$ coordinates to ease the implementation of the ACO algorithm (see Table 1). Another important part of this analysis was the determination of a distance matrix by calculating the shortest driving distance between each of the 148 points including the disposal ground (see Table 2).

Table 1. A portion of the coordinates and the number of containers of each collection point

\begin{tabular}{|c|c|c|c|}
\hline Collection point & Point_x & Point_y & Number of containers \\
\hline 1 & 4154499 & 4442535 & 2 \\
\hline 2 & 4154542 & 4442643 & 2 \\
\hline 3 & 4154648 & 4442849 & 1 \\
\hline 4 & 4154466 & 4442937 & 2 \\
\hline 5 & 4154433 & 4442983 & 2 \\
\hline 6 & 4154337 & 4442777 & 1 \\
\hline 7 & 4154325 & 4442692 & 4 \\
\hline 8 & 4154156 & 4442895 & 2 \\
\hline 9 & 4154223 & 4442994 & 5 \\
\hline 10 & 4154237 & 4443017 & 1 \\
\hline 11 & 4154092 & 4443080 & 2 \\
\hline 12 & 4154268 & 4443099 & 1 \\
\hline 13 & 4154293 & 4443080 & 2 \\
\hline
\end{tabular}


Table 2. A portion of the distance matrix between collection points

\begin{tabular}{|c|c|c|}
\hline Input_fid & Near_fid & Distance (Meters) \\
\hline 1 & 2 & 116.24543 \\
\hline 1 & 3 & 347.5586281 \\
\hline 1 & 4 & 403.3522034 \\
\hline 1 & 5 & 452.835511 \\
\hline 1 & 6 & 291.2181313 \\
\hline 1 & 7 & 234.3608329 \\
\hline 1 & 8 & 497.2413901 \\
\hline 1 & 9 & 535.5903285 \\
\hline 1 & 10 & 548.6055049 \\
\hline 1 & 11 & 680.2014408 \\
\hline 1 & 12 & 609.4727229 \\
\hline 1 & 13 & 582.6328175 \\
\hline & 14 & 452.0995466 \\
\hline
\end{tabular}

\subsection{Implementation of the ACO Algorithm}

The process of applying the ACO algorithm on our CTSP problem is made of several coding procedures including determining the initial parameters, creating ant colonies, applying the roulette wheel, calculating the fitness function, finding the best ant, updating the pheromone matrix, performing an evaporation and visualization of the results. The algorithm codes were written on MATLAB R2018b and computation was carried out on a computer that has an Intel(R) Core(TM)@2.20 GHz processor with 8Gb RAM. Initializing the ACO parameters is the first and probably the most important stage of implementing the algorithm. These parameters to be set are a number of ants $(A)$, the number of iterations $(T)$, initial pheromone level $\left(\tau_{0}\right)$, rate of evaporation $(\rho)$, pheromone heuristic factor $(\alpha)$ and expected heuristic factor $(\beta)$.

Because the number of ants can reasonably be set to the number of destinations in the given TSP (Gaertner \& Clark, 2005). We set as 148 ants in our case. Concerning the heuristic factors and the rate of evaporation, ACO is too complex to allow for an analytical approach to the problem of optimizing parameter settings (Siemiński 2013). Several experiments have been performed in the past in an attempt to determine the values of $\alpha$ and $\beta$ that produce the lowest cost. Gaertner and Clark, 2005 [15] have emphasized the importance of avoiding extreme values for $\alpha$ and $\beta$, which would affect the global searching ability and the searching speed of the algorithm. Accordingly, based on the parameter evaluation examples and simulations performed by Gaertner and Clark, 2005 [15] $\alpha$ is recommended to be in the interval $[1.0,3.0], \beta$ is set in the range $[2.0,4.0]$, whereas $\rho$ falls in the interval $[0.5,0.8]$. We have set $\alpha=1.0, \beta=2.0$ and $\rho=0.5$.

The initial pheromone concentration, on the other hand, has been calculated using the following Equation 5.

$\tau_{o}=\frac{10}{\sum_{i=1}^{n} \sum_{j=2}^{n} d i j}(n-1)$ 
where $n$ is the number of nodes

$d_{\mathrm{ij}}$ is the distance between node $i$ and node $j$

The number of nodes (collection points and a disposal ground) in our problem is 148, and given the distance matrix, we have calculated the initial pheromone concentration $\tau_{\mathrm{o}}$ to be $1.42 * 10 \mathrm{e}-6$. To achieve a solution as close to the optimal value as possible, we have performed 1041 iterations, thus setting $T=1041$.

The next step in the implementation of the ACO algorithm is the creation of a colony of ants that will tour the graph looking for the shortest route possible. The pseudo-code in Figure 3 illustrates the process used to create ant colonies for our study:

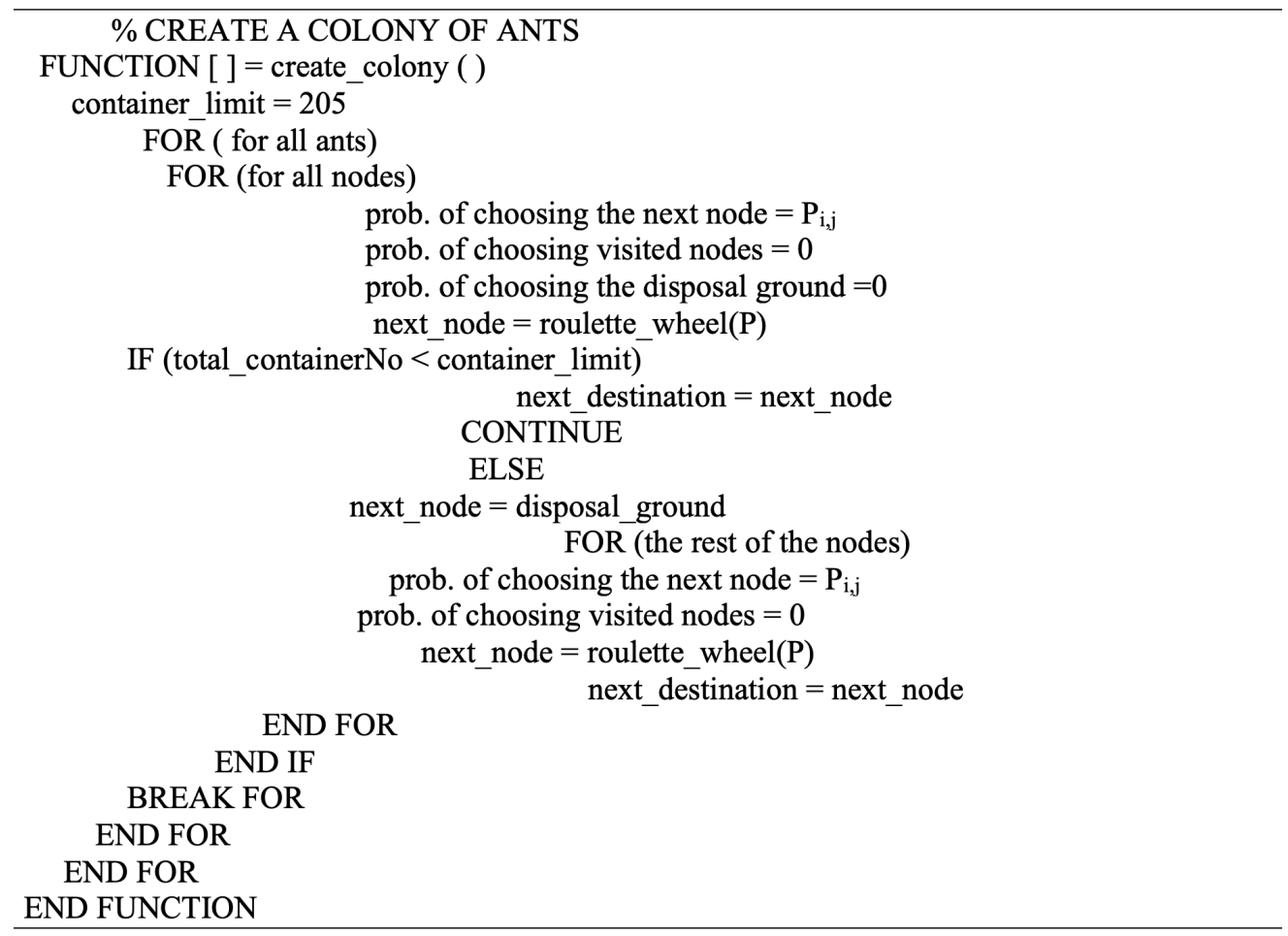

Figure 3. Pseudo-code for creating a colony of ants

Whenever an ant $k$ completes a tour visiting all the collection points, the length of its tour $\left(\mathrm{L}_{\mathrm{k}}\right)$, the sum of the length of the edges traveled by the ant, and the sequence of the collection points visited (the tour of ant $k$ ) are saved in the fitness function. A fitness value corresponding to ant $k$ represents the length of its tour $\left(L_{\mathrm{k}}\right)$. In each iteration, the fitness values of all ants are compared with each other, and the smallest fitness value is stored as 'the best fitness'. The tour corresponding to the ant with the smallest fitness value will also be stored as 'the best tour'. These values are updated whenever a new fitness function is created in every iteration. The process of updating the pheromone levels of the 'good solutions' is also carried out using the values obtained from the fitness function. If ant $k$ used the edge $i, j$ in its route, the pheromone concentration of edge $i, j$ would be improved by an amount equal to the reciprocal of the fitness value of ant $k$, (as given in Equation 1). The pheromone updating step in each iteration is preceded by evaporation (see Eq. 3) corresponding to a rate $\rho=0.5$, meaning half of the pheromone 
level in the 'bad solutions' will be destroyed. The following flow chart given in Figure 4 that summarizes the steps followed while implementing the ACO algorithm:

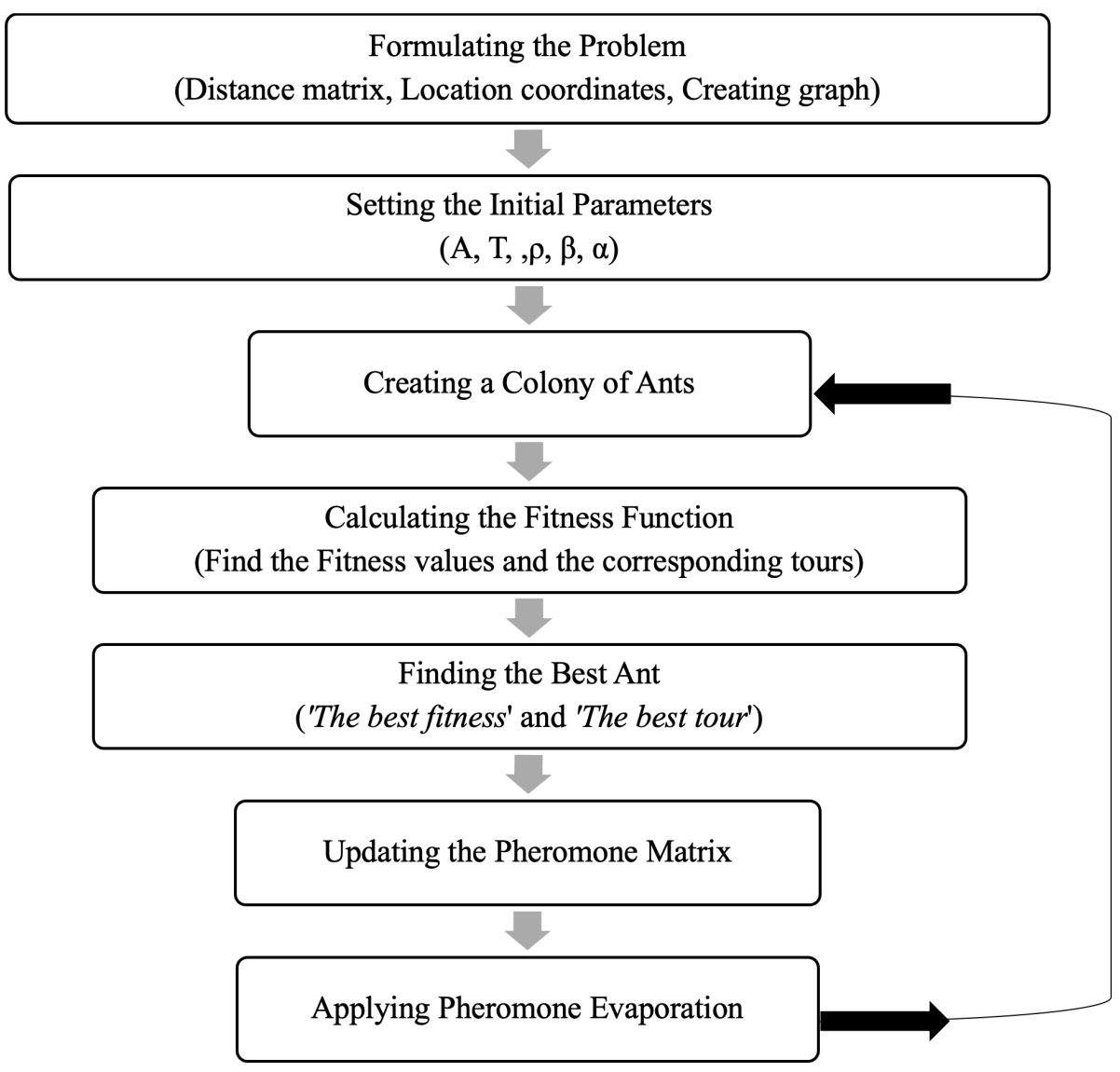

Figure 4. Procedure for implementing ACO algorithm

\subsection{Computational analysis of the pilot problem}

To demonstrate the computational performance and feasibility of the ACO algorithm and MILP, a pilot case problem is extracted from our original case. 9 of the 148 collection points have been modeled as a TSP to demonstrate the feasibility and computational time of the ACO algorithm and MILP. We began by finding the sub-solution of the TSP using MILP. First, a $9 \times 9$ matrix was selected to show the distance relationship between the collection points. The distance matrix is shown in Table 3.

Table 3. The distance matrix for the pilot problem.

\begin{tabular}{|l|l|l|l|l|l|l|l|l|l|}
\hline & $\mathbf{1}$ & $\mathbf{2}$ & $\mathbf{3}$ & $\mathbf{4}$ & $\mathbf{5}$ & $\mathbf{6}$ & $\mathbf{7}$ & $\mathbf{8}$ & $\mathbf{9}$ \\
\hline $\mathbf{1}$ & 0 & 116,2454 & 347,5586 & 403,3522 & 452,8355 & 291,2181 & 234,3608 & 497,2414 & 535,5903 \\
\hline $\mathbf{2}$ & 116,2454 & 0 & 231,6722 & 303,6643 & 357,0448 & 244,9102 & 222,4635 & 460,9772 & 474,3016 \\
\hline $\mathbf{3}$ & 347,5586 & 231,6722 & 0 & 202,1584 & 253,3397 & 319,2256 & 359,1351 & 494,1457 & 449,0546 \\
\hline $\mathbf{4}$ & 403,3522 & 303,6643 & 202,1584 & 0 & 56,61272 & 205,5262 & 282,6765 & 312,8322 & 249,5957 \\
\hline $\mathbf{5}$ & 452,8355 & 357,0448 & 253,3397 & 56,61272 & 0 & 227,2708 & 310,3949 & 290,6424 & 210,2879 \\
\hline $\mathbf{6}$ & 291,2181 & 244,9102 & 319,2256 & 205,5262 & 227,2708 & 0 & 85,84288 & 216,0671 & 245,1224 \\
\hline $\mathbf{7}$ & 234,3608 & 222,4635 & 359,1351 & 282,6765 & 310,3949 & 85,84288 & 0 & 264,1401 & 318,7601 \\
\hline $\mathbf{8}$ & 497,2414 & 460,9772 & 494,1457 & 312,8322 & 290,6424 & 216,0671 & 264,1401 & 0 & 119,5408 \\
\hline $\mathbf{9}$ & 535,5903 & 474,3016 & 449,0546 & 249,5957 & 210,2879 & 245,1224 & 318,7601 & 119,5408 & 0 \\
\hline
\end{tabular}


The codes were then written on LINGO Extended Version and computation was carried out on a computer with Intel(R) Core(TM)@2.20 GHz processor with 8Gb RAM. The proposed MILP model is suitable for small TSP problems such as our pilot problem.

The optimal sequence of the collection points of pilot problem is also shown as below;

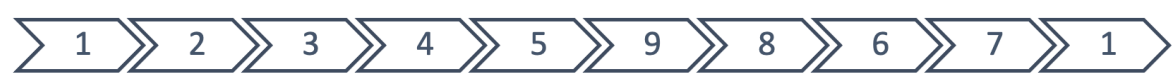

In the second stage, the ACO algorithm was applied to the same set of collection points modeled as a TSP. 500 iterations are performed and the number of ants is now set at $A$ $=9$ to account for the change in the number of locations. The remaining parameters are used as determined in Section 3.2. Figure 5 shows the solution space of the pilot problem:

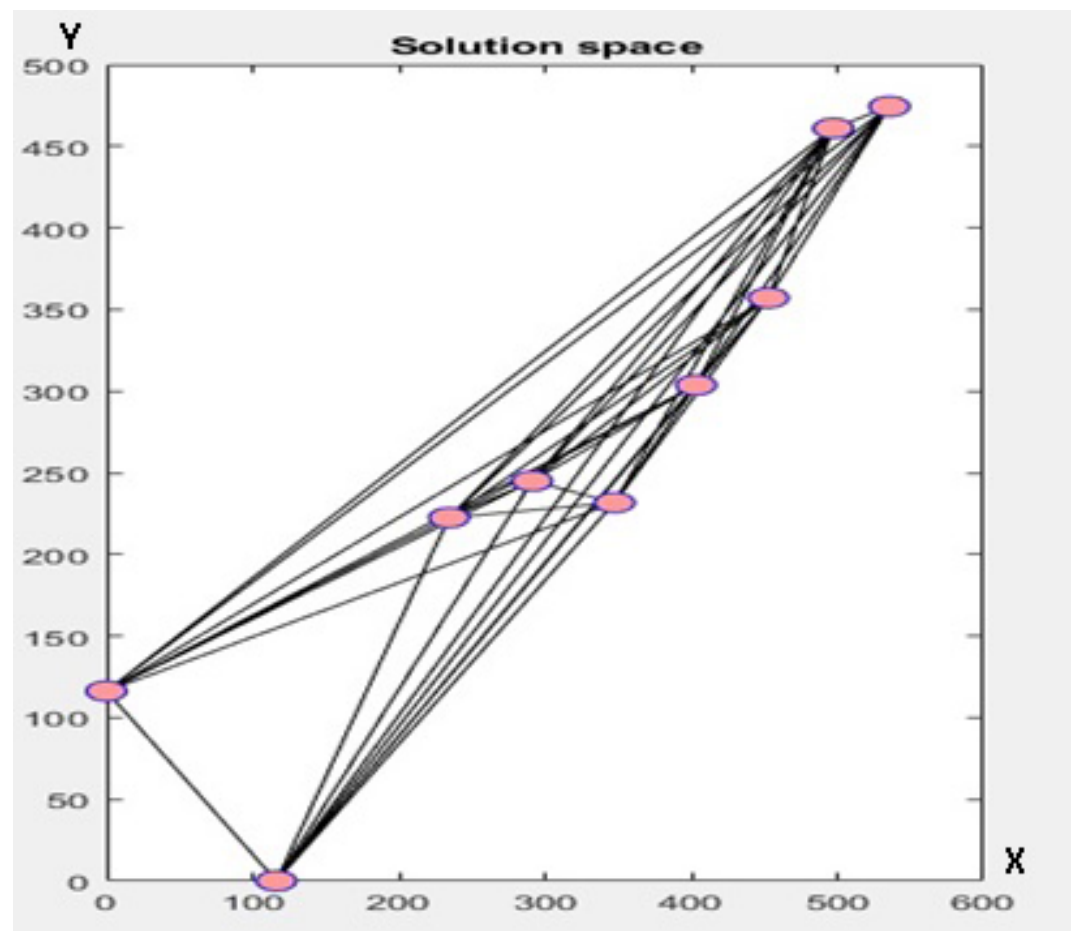

Figure 5. Solution space of the pilot problem with 9 collection stops

The algorithm was coded to undergo several iterations; the tour of the best ant and the distribution of the pheromone trails are illustrated. Figure 6 portrays the graphical results after 4 iterations and it gives a good visualization of what the pheromone distribution looks like in the early stages of the optimization algorithm. On the other hand, in the pheromone trail graph of Figure 7, it can be observed that after a series of pheromone updating and evaporation procedures, all the pheromone remains are concentrated on the tour of the best ant. This phenomenon shows the importance of updating pheromones to promote good solutions, while evaporation gradually destroys bad solutions. 

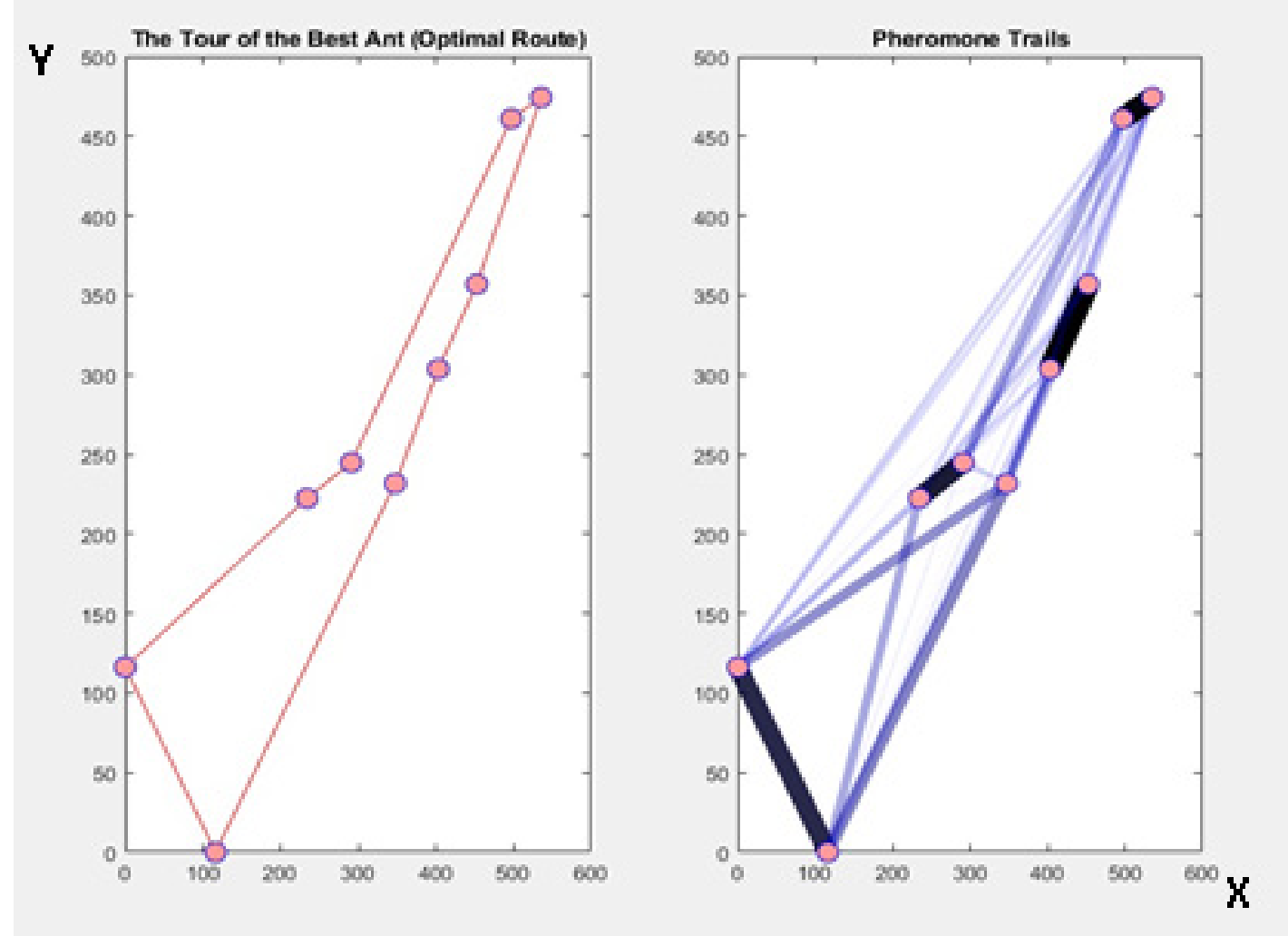

Figure 6. Visualization of the ACO solution after 4 iterations

The shortest path at the highest iteration has been determined to be 1472.7882 meters approximately $1.5 \mathrm{Km}$, which agrees with the global optimal solution obtained using MILP. Thus, the shortest path provided by the ACO algorithm is also the optimal route of the pilot TSP. It is also observed from Figure 6 that it took the algorithm only 4 iterations to reach the global optimal solution obtained using LINGO's MILP. This can be explained by the fact that the solution space of the problem is too small when compared to the performance of the algorithm. In this case, ant colonies have a high probability of narrowing the solution space quickly by following pheromone trails concentrated on comparatively shorter paths that get visited more frequently than their longer counterparts due to their higher desirability and quality. The total computational time after 500 iterations for the father function (AntColonyAlg) that executes all the other child functions is observed to be 2.78 minutes, which is poor when compared to the total elapsed time of 0.13 seconds consumed during MILP. This emphasizes the performance superiority of linear programming over heuristic methods for solving small-scale problems. The optimal route and the pheromone trail distribution for the pilot problem have been shown in Figure 7. 

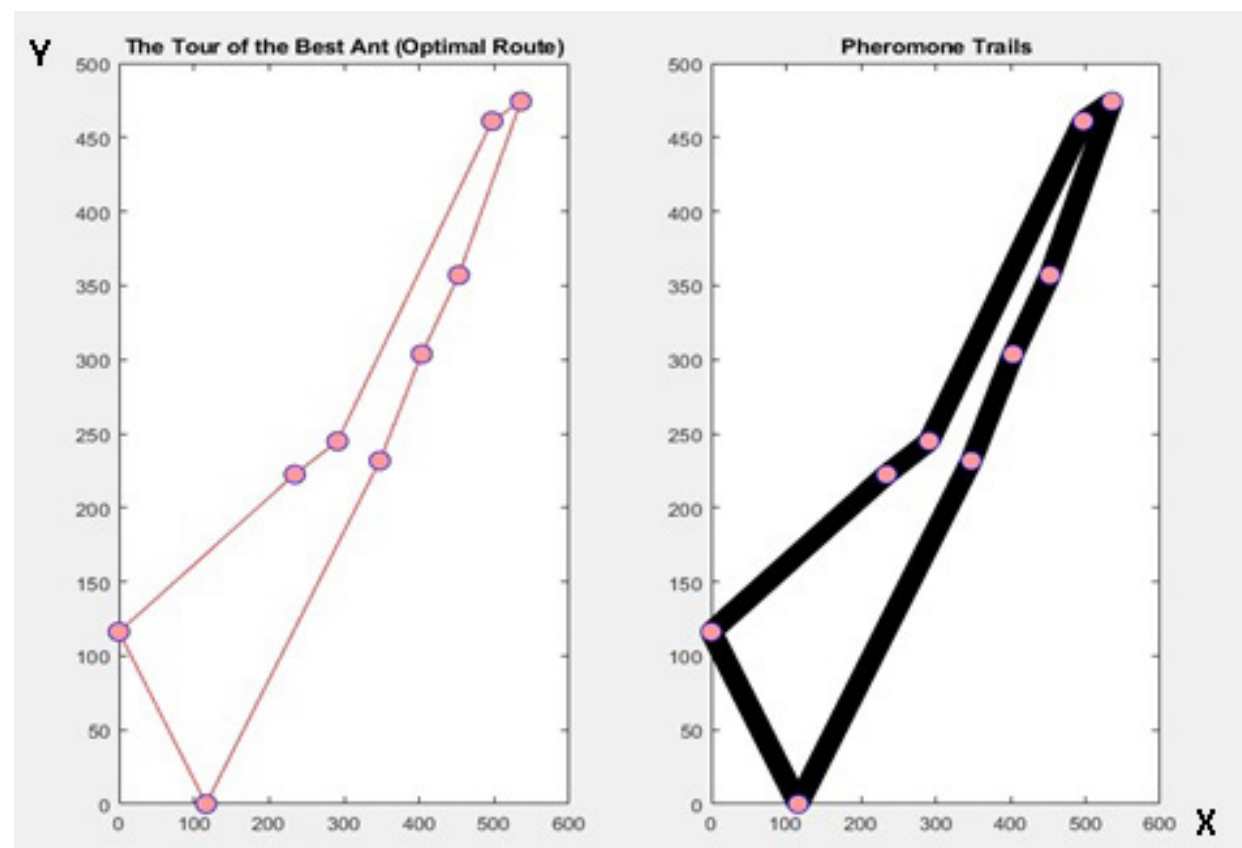

Figure 7. The optimal route and the pheromone trail distribution in the pilot problem

\subsection{Computational analysis for the real case problem}

The original CTSP is made up of 349 residential waste containers divided into 148 collection points. As mentioned in Section 2, the ACO algorithm to this CTSP problem has been written taking the capacity constraint into account. Once the garbage compactor vehicle has collected waste from a maximum of 200 containers, it travels to the disposal ground, unloads, and then returns to the remaining collection points. This phenomenon is effectively modeled and illustrated in Fig. 9. The parameters of the ACO algorithm in this study are $T=1041, \tau_{\mathrm{o}}=1.42 * 10 \mathrm{e}-6, \alpha=1.0, \beta=2.0$ and $\rho=0.5$. Based on the procedure set in Figure 4, the ACO algorithm was written on MATLAB R2018b, and computation was carried out on a computer, which has an Intel(R) Core(TM) @2.20 GHz processor with $8 \mathrm{~Gb}$ RAM. This NP-Hard problem has an extremely large solution space due to the existence of a large number of locations with 148 collection points. By the way, the solution space consists of 148 factorial combinations. The shortest distance traveled by the best ant in the early, middle and final iterations show a decent reduction in value thus indicating an increase in the quality of the solution as the iteration proceeds. In the first 9 iterations of the algorithm, the shortest route has seen a 35\% improvement dropping to just below $31 \mathrm{~km}$ from an initial value of over $47 \mathrm{~km}$ in the first iteration. However, this reduction in the shortest route doesn't show a significant decline in the remaining iterations. The algorithm reached its near-optimal distance of roughly 29.5 $\mathrm{km}$ at the $169^{\text {th }}$ iteration and remained unchanged until the 1041 st iteration. This early arrival to the near-optimal solution and inability to improve in the late iterations can be attributed to the relative proximity of the waste containers to each other, thus creating a condition where the possibility of finding a better solution than achieved after some point becomes difficult or is accompanied by insignificant changes. 
Using the ACO algorithm the optimal route of the CTSP is presented in Table 4:

Table 4. The results of the capaciated travelling salesman problem for the 148 containers

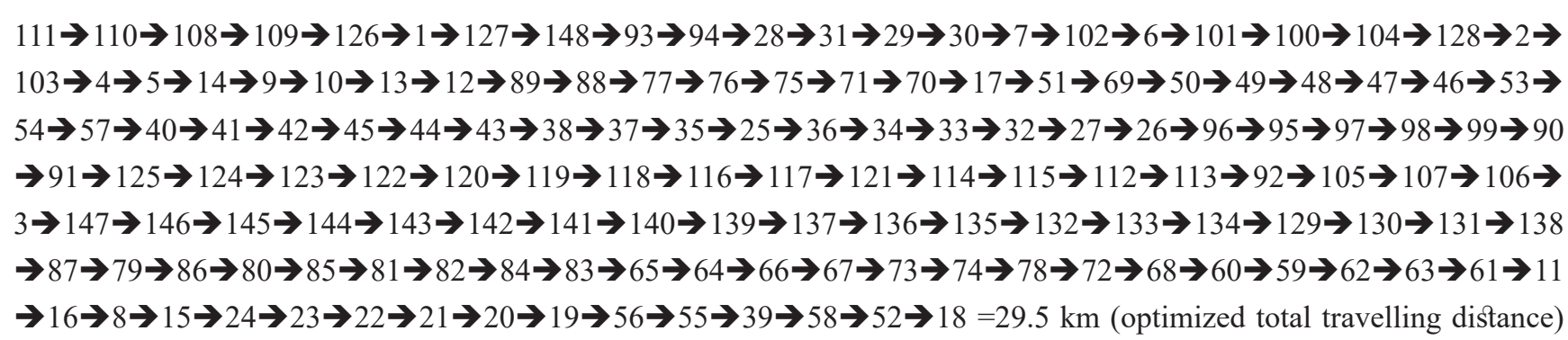

The solution time for the functions implemented in the proposed ACO algorithm is shown in Table 5. The computational time is just over 10 hours $(37,177 \mathrm{sec})$. However, the computational time it took the ACO algorithm to find the shortest route should be significantly lower than the current termination time as the algorithm reached its nearoptimal value much earlier (in the $169^{\text {th }}$ iteration).

Table 5. The computational time of the ACO algorithm

\begin{tabular}{|l|l|l|l|}
\hline $\begin{array}{l}\text { Summary } \\
\text { Function name }\end{array}$ & Calls & Total Time & Self Time* \\
\hline drawPheromone & 1041 & $28048.507 \mathrm{~s}$ & $20018.750 \mathrm{~s}$ \\
\hline AntColonyAlg & 1 & $37177.325 \mathrm{~s}$ & $4611.319 \mathrm{~s}$ \\
\hline gobjects & 23592375 & $2242.759 \mathrm{~s}$ & $2242.752 \mathrm{~s}$ \\
\hline newplot & 11796187 & $6267.129 \mathrm{~s}$ & $1986.235 \mathrm{~s}$ \\
\hline Graphics/private/clo & 2082 & $1927.782 \mathrm{~s}$ & $1927.782 \mathrm{~s}$ \\
\hline newplotwrapper & 11796187 & $7842.138 \mathrm{~s}$ & $1575.009 \mathrm{~s}$ \\
\hline Newplot>ObserveAxesNextPlot & 11796187 & $1409.440 \mathrm{~s}$ & $1409.440 \mathrm{~s}$ \\
\hline Title & 2083 & $788.923 \mathrm{~s}$ & $788.313 \mathrm{~s}$ \\
\hline CreateColony & 1042 & $1091.923 \mathrm{~s}$ & $723.212 \mathrm{~s}$ \\
\hline Newplot>ObserveFigureNextPlot & 11796187 & $628.709 \mathrm{~s}$ & $628.709 \mathrm{~s}$ \\
\hline drawBestTour & 1041 & $1183.553 \mathrm{~s}$ & $453.360 \mathrm{~s}$ \\
\hline rouletteWheel & 22655199 & $175.738 \mathrm{~s}$ & $175.738 \mathrm{~s}$ \\
\hline updatePheromone & 1041 & $165.027 \mathrm{~s}$ & $165.027 \mathrm{~s}$ \\
\hline iofun/private/openExcelWorkbook & 1044 & $124.951 \mathrm{~s}$ & $116.004 \mathrm{~s}$ \\
\hline Hold & 156151 & $138.773 \mathrm{~s}$ & $89.489 \mathrm{~s}$ \\
\hline Graphics/private/claNotify & 2082 & $80.629 \mathrm{~s}$ & $80.361 \mathrm{~s}$ \\
\hline markFigure & 162397 & $30.929 \mathrm{~s}$ & $30.929 \mathrm{~s}$ \\
\hline
\end{tabular}

\section{Discussion and Conclusion}

This paper has successfully demonstrated the performance of the meta-heuristic ant colony optimization algorithm to a capacitated travel salesman problem of a solid waste collection vehicle in the Güneykent district. A pilot problem extracted from the original CTSP has also been modeled as a TSP to assess the performance and feasibility of the proposed ACO algorithm and compare its solution to that of an exact optimization method namely the MILP model. 
Such as particle swarm optimization, firefly algorithm, ant colony optimization, and bat algorithm have gained much popularity and they have successfully tackled various test suites of benchmark functions and real-world problems. It was inevitable to use ant colony or similar algorithms to solve our combinatorial problem. Based on our existing experience on ACO algorithm, it was able to approximate promising solutions with good convergence and diversity maintenance for most of the optimization problems.

It has been observed that the ACO algorithm has delivered the same solution as the global optimal solution provided by the MILP on LINGO. The computational time on LINGO $(0.13 \mathrm{sec})$ was, however, significantly lower than the termination time of the ACO algorithm (2.78 min) implemented in MATLAB, emphasizing the superiority of exact models and linear solvers over heuristic methods in optimizing small scale TSPs.

The application of the proposed ACO algorithm on the original CTSP has shown satisfactory results. The shortest possible route (near-optimal distance) was determined to be $29.5 \mathrm{~km}$. As per the solution obtained, the garbage compactor truck will visit 84 of the 148 collection points before heading to the disposal ground to unload, during which 196 of the 349 residential solid waste containers will be visited, thus satisfying the capacity constraint. The remaining collection points will then be visited in the second round. In spite of the 10 hours termination time to complete around a thousand iterations, the algorithm has managed to reach the near-optimal solution in the $169^{\text {th }}$ iteration, on which the shortest route was $29.5 \mathrm{~km}$.

The length of the current solid waste collection and transportation route followed by the garbage compactor truck understudy in the Güneykent district was $41 \mathrm{~km}$. As a result, the near-optimal solution obtained as a result of the ACO algorithm $(29.5 \mathrm{~km})$ is found to be a significant improvement. There exists a daily reduction of $11.5 \mathrm{~km}$ ( $28 \%$ reduction) of driving distances in the new solution. In practice, waste collection vehicles operate daily using the same route. So, these statistics reach $345 \mathrm{~km}$ per month and a further 4,197.5 $\mathrm{km}$ saving every year from just a single truck. Eventually, the new route will considerably reduce labor costs, the high price of fuel, machinery and equipment maintenance as well as environmental pollution. Because garbage compactor trucks are one of the least efficient vehicles on the road, a quick calculation of the reduction in fuel costs introduced by the new route shows that with the current fuel price averaging 6 ₹ per liter and given the fact that the truck understudy consumes 1 liter of diesel fuel for every $1.5 \mathrm{~km}$ of waste collection and transportation, the optimized route would bring about a saving of 16,790 € per year per vehicle. This lends a considerable economic benefit when compared to the current expenditure of the district reaching 58,400 $€$ per year per vehicle. The saving accounts to close to $30 \%$ of the current expenditure.

The potential future benefit of this study can be easily anticipated when because the SWMS in Şahinbey Municipality has over 50 garbage compactor trucks operating in the much longer and complicated collection and transportation routes and routines in different districts of the municipality every day. Thus, a deep study and analysis of the existing routing system, as well as the application of meta-heuristic or other heuristic optimization 
techniques to optimize waste collection and transportation routes, is key to promoting significant cost reductions and improving the efficiency of the SWMS in general.

Due to their low efficiency and consumption of diesel fuel, garbage compactor tracks are also highly pollutant, thus making every mile reduction valuable. A reduction of $4,197.5 \mathrm{~km}$ per year per vehicle brought about by the new route will provide a considerable decline in the amount of carbon dioxide emitted to the environment. This study can also be adapted and/or modified to include other districts in the municipality to be able to experience more significant and visible economic and environmental changes. It can also be studied under integrated SWMS along with other study areas including optimal container location, collection schedule, and vehicle assignment.

Capacitated garbage collection management problem is a combinatorial problem. For example; if there are three waste containers, there will be possible three factorial routes to visit. As the number of waste containers increases, the number of problem variables increases exponentially. In addition, other constraints that make it difficult, especially capacity constraints, do not allow the collection of waste with unlimited time and unlimited storage. The insolvency of the problem with mathematics depends on the variables of the problem. Therefore, it can take days to months to obtain the optimal solution. The difficulty of the problem will increase with new constraints. If the working hours, experiences, special requests and work of the employees are taken, the problem may become unsolvable. While we always move towards solving more realistic problems, the endless buffers follow each other because the dynamics of work and life do this in the future. This is why our model is built on an important problem of garbage collection as a vehicle routing problem. The problem is very clear and its purpose is very simple. In future studies, it is necessary to make new simple and realistic additions to this problem, whose goal is clear. For example, the types of waste collected, sorting facilities, waste collection priorities; neighborhood or route priorities can be added. This increases the importance of the problem even more, and if it is made more dynamic, more beneficial results will result.

Peer-review: Externally peer-reviewed.

Conflict of Interest: The authors have no conflict of interest to declare.

Grant Support: The authors declared that this study has received no financial support.

Hakem Değerlendirmesi: Dış bağımsız.

Çıkar Çatışması: Yazarlar çıkar çatışması bildirmemiştir.

Finansal Destek: Yazarlar bu çalışma için finansal destek almadığını beyan etmiştir.

\section{References}

Abdallah, M. Talib, M.A. Feroz, S., Nasir, Q. Abdalla, H. and Mohfood, B. (2020). Artificial intelligence applications in solid waste management: A systematic research review. Waste Management, 109: 231-246.

Bilgi Ö. (2008). Solid Waste Management in Turkey. GSI Articletter, 32, Fall 2011.

Beijoco, F. Semião, V. Zsidgraiová, Z. (2011). Optimization of a municipal solid waste collection and transportation system. https://www.semanticscholar.org/paper/optimization-of-a-municipal-solid-wastecollection-beijoco-semião/8c0c39263e12949bf94247b7b32ed2522091a868. pdf adresinden erişildi. 
Bhambulkar, A.V. (2011). Municipal Solid Waste Collection Routes Optimized with ARC GIS Network Analyst. International Journal Of Advanced Engineering Sciences And Technologies, 11(1): 202-207.

Chen, J. (2016) Parameters Evaluation of Colony Algorithm based on TSP. Rev. Téc. Ing. Univ. Zulia, 39 (4): 121-126.

Choroś K., Siemiński A. (eds) (2013) Multimedia and Internet Systems: Theory and Practice. Advances in Intelligent Systems and Computing, Springer, Berlin, Heidelberg. 183: 143-153.

Dorigo, M. Ant Colony Optimization. Scholarpedia, 2(3): 1462, 2007.http://www.scholarpedia.org/article/ Ant_colony_optimization. Adresinden erişildi.

Dorigo M. Stützle, T. (2004). Ant colony optimization, A Bradford Book, The MIT Press, Cambridge, Massachusetts.

Das, S. Bhattacharyya, B.K. (2015). Optimization of municipal solid waste collection and transportation routes, vol. 43, pp. 9-18, September.

Gaertner, DClark, K. (2005). On Optimal Parameters for Ant Colony Optimization Algorithms," In Proc. International Conference on Artificial Intelligence.

Gören S, and Özdemir F., (2011). Regulation of waste and waste management in Turkey Waste Management\&Research, 29: 433.

Hannan, M.A. Akhtar, M. Begum, R.A. Basri, H. Hussain, A. Scavino, E. (2018). Capacitated Vehicle-Route Problem Model for Scheduled Solid Waste Collection and Route Optimization Using PSO Algorithm. Waste Management. 71: 31.

Hanna, M.A., Hossain Lipu H.S., Akhtar M., Begum R.A., Al Mamun A. Hussain A., Mia M.S., Basri, H., (2020) Solid waste collection optimization objectives, constraints, modeling approaches, and their challenges toward achieving sustainable development goals. Journal of Cleaner Production, Vol: 277, 123557.

Islam, R. Rahman, M. S. (2012). An ant colony optimization algorithm for waste collection vehicle routing with time windows driver rest period and multiple disposal facilities," In Proc. Informatics Electronics \& Vision (ICIEV) International Conference on IEEE. 774-779.

Karadimas, N.V. Papatzelou, K. Loumos, V.G. (2007). Genetic Algorithms for Municipal Solid Waste Collection and Routing Optimization. International Federation for Information Processing Digital Library; Artificial Intelligence and Innovations,: from Theory to Applications. 247: 223-232.

Köse Ö.H, Ayaz S, and Köroglu B (2007). Waste Management in Turkey: National Regulations and Evaluation of Implementation Results. Turkish Court of Accounts, Performance Audit Report 5181/1: 75.

Liu, L., Liao W. (2021) Optimization and profit distribution in a two-echelon collaborative waste collection routing problem from economic and environmental perspective, Waste Management. Vol: 120, pp. 400-414.

Mamashli, Z., Javadian N., (2020) Sustainable design modifications municipal solid waste management network and better optimization for risk reduction analyses, Journal of Cleaner Production, Vol: 279, 123824.

Mojtahedi M., Fathollahi-Fard Amir M., Moghaddam, R. T., Newton S., (2021) Sustainable vehicle routing problem for coordinated solid waste Management, Journal of Industrial Information Integration, Vol: 23, 100220.

Nguyen XC., Nguyen TTH., La DD., Kumar G., Rene E.R., Nguyen D.D., Chung SW., Chung WJ., Nguyen XH., Nguyen VK., (2021). Development of machine learning based models to forecast solid waste generation in residential areas: A case study from Vietnam, Resources, Conservation \& Recycling, 167: 105381.

Siemiński A., (2013). Ant Colony Optimization Parameter Evaluation. Multimedia and Internet Systems: Theory and Practice. 143-153.

Talebbeydokhti, N. Amiri, H. Shahraki, M.H. Azadi S., Ghahfarokhi, S.G. (2013) “Optimization of Solid Waste Collection and Transportation System by Use of the TransCAD: A Case Study”, ArchHyg Sci; 2(4): 150-7.

Tavares, G. Zsigraiova, Z. Semiao, V. Carvalho, M.G. (2009). Optimization of MSW collection routes for minimum fuel consumption using 3D GIS modeling. Waste Management. 29(3): 1176-1185. 
